\title{
New ESO/ESMINT Thrombectomy Guidelines: after Guideline Writing is before Guideline Writing
}

\author{
Jens Fiehler ${ }^{1}$ \\ Published online: 9 May 2019 \\ ๑) Springer-Verlag GmbH Germany, part of Springer Nature 2019
}

In late February, the new European guidelines on mechanical thrombectomy for the treatment of stroke patients have been published online in free access [1]. This document was primarily drafted by the European Stroke Organization (ESO) and European Society of Minimally Invasive Neurological Therapy (ESMINT) and is now endorsed by the German Society of Neuroradiology (DGNR) in the meeting of its executive board on 9 May 2019. To repeat this successful joint European guidelines effort on a national level seemed hardly justified, even if comprehensive care for acute stroke patients is already a reality in Germany [2] and national guidelines might address slightly different questions than European ones.

Like any clinical discipline, interventional neuroradiology needs to systematically analyze and evaluate existing clinical studies and to draw practical conclusions. If we do not do this ourselves, others will. In such cases, we are often not happy with the results and this time, we should rather be happy.

Recommendations and guidelines tend to be located somewhere in the range from science based to completely opinion focused. Either the document reflects mainly expectations and standards set by key opinion leaders ("ten old boys sitting around a table", TOBSAT) or they are mainly written around existing high-class external evidence. The new European guidelines certainly belong to the latter, not only because not only "old boys" were involved.

The new guidelines were developed based on the EROICAS recommendations from 2016 [3] but are now following the advanced Grading of Recommendations, Assessment, Development, and Evaluation (GRADE) approach [4], ensuring the highest possible degree of objectivity. A total of 11 experts jointly followed this predefined standardized process and generated 15 highly standardized

Jens Fiehler

fiehler@uke.uni-hamburg.de

1 Klinik und Poliklinik für Neuroradiologische Diagnostik und Intervention, UKE Hamburg, Hamburg, Germany questions and conducted subject specific meta-analyses of the scientific literature. Based on the quality of the scientific evidence, the committee made weak or strong recommendations for different patient groups and different therapy approaches; however, many recommendations are still somewhat vague because of limited scientific evidence to back them up. To still allow some practical guidance in all important questions, expert opinions were provided whenever not enough evidence was available to provide clear recommendations.

Why do we need guidelines at all? Of course, each of us could and should scan and interpret the scientific literature regularly to be up to date in clinical decision making; however, this process is time-consuming, most probably less standardized and complete, more error prone, and perhaps even somewhat biased to confirm our pre-existing expectations. If we hand this process to a committee instead, there is higher credibility because of its interdisciplinary constitution and the lower likelihood of individual interests dominating the recommendations. The high credibility of guidelines can be helpful for discussions with hospital administrators, e.g. to ask for resources but also on a national or international level for resource allocation and reimbursement questions.

An important part is the definition of qualification criteria for centers and interventionalists. Based on the "gold coast document" [5], an operator must have a "dedicated training in interventional neuroradiology ... under the direction of a neurointerventionalist ... at a high-volume centre". It is clearly pointed out in the guidelines that these requirements are not just a claim to be used for turf battles and politics: "The generalizability of the trial findings to centres or interventional teams that do not fulfil these criteria is not established by the literature."

While the overall benefit of thrombectomy was beyond any doubt [6], addressing the role of advanced imaging such as computed tomography perfusion and magnetic resonance perfusion remained a challenging task. The guidelines state that "... in ... patients presenting from 0 to $6 \mathrm{~h} \mathrm{...,}$ advanced imaging is not necessary ..." while "beyond $6 \mathrm{~h} \mathrm{...,}$ 
advanced imaging selection is necessary." An interesting practical notion is that "... regions with limited mechanical thrombectomy (MT) resources should apply the most advanced imaging capabilities available for strict patient selection." [1]. This simpler and more flexible imaging approach clearly differs from the very strict recommendations of the American Heart Association (AHA) [7]. These guidelines require sticking to the very specific study imaging criteria to the letter, separately in the $6-16 \mathrm{~h}$ and the $16-24 \mathrm{~h}$ time windows; however, I feel that this is evidence taken too far. Any study results need to be applicable also beyond the strict boundaries of the trial (external validity), at least in terms of its participating centers and the time period. Otherwise a trial would be pointless and this external validity should be subject to reasonable debate. Although the European guidelines on patient selection seem somewhat blurry to some degree, they give the practitioners the required space.

An important feature of an elaborated guideline process is the approval by several independent committees and boards which makes it very time-consuming. Therefore, such guidelines are outdated the moment that they are published. A central example in these guidelines is that they did not include the COMPASS study that was published about 2 weeks after the publication of the guidelines [8]. This study supports the use of direct aspiration as an alternative to stent retriever as first-line therapy for stroke thrombectomy. The authors of the guidelines tried to take the COMPASS conference presentation into account in the expert opinions but not in the official recommendation ("ADAPT may be used as standard first-line treatment ...") [1].

This leaves the impression that guidelines are never final and that writing the next version of these guidelines is due in a not too distant future. Perhaps, we can then include some more studies with central involvement of DGNR and Austrian Society of Neuroradiology (ÖGNR) members [9]. Hopefully, some more members are going to participate in guideline writing itself. In any case, to paraphrase Sepp Herberger, after guideline writing is before guideline writing!
Conflict of interest J. Fiehler declares that he has no competing interests.

\section{References}

1. Turc G, Bhogal P, Fischer U, Khatri P, Lobotesis K, Mazighi M, Schellinger PD, Toni D, de Vries J, White P, Fiehler J. European Stroke Organisation (ESO)-European Society for Minimally Invasive Neurological Therapy (ESMINT) guidelines on mechanical thrombectomy in acute ischemic stroke. J Neurointerv Surg. 2019. https://doi.org/10.1136/neurintsurg-2018-014569

2. Berlis A, Morhard D, Weber W. Flächendeckende Versorgung des akuten Schlaganfalls im Jahr 2016 und 2017 durch Neuro-Radiologen mittels mechanischer Thrombektomie in Deutschland anhand des DeGIR/DGNR-Registers. Rofo. 2019. https://doi.org/10.1055/ a-0857-6694

3. Fiehler J, Cognard C, Gallitelli M, Jansen O, Kobayashi A, Mattle HP, Muir KW, Mazighi M, Schaller K, Schellinger PD. European Recommendations on Organisation of Interventional Care in Acute Stroke (EROICAS). Int J Stroke. 2016;11:701-16.

4. Guyatt GH, Oxman AD, Schünemann HJ, Tugwell P, Knottnerus A. GRADE guidelines: a new series of articles in the journal of clinical epidemiology. J Clin Epidemiol. 2011;64:380-2.

5. American Academy of Neurological Surgeons/Congress of Neurological Surgeons (AANS/CNS). Training guidelines for endovascular Ischemic stroke intervention: an international multi-society consensus document. J Neurointerv Surg. 2016;8:989-91.

6. Bhogal P, Andersson T, Maus V, Mpotsaris A, Yeo L. Mechanical thrombectomy-a brief review of a revolutionary new treatment for thromboembolic stroke. Clin Neuroradiol. 2018;28:313-26.

7. Powers WJ, Rabinstein AA, Ackerson T, Adeoye OM, Bambakidis NC, Becker K, Biller J, Brown M, Demaerschalk BM, Hoh B, Jauch EC, Kidwell CS, Leslie-Mazwi TM, Ovbiagele B, Scott PA, Sheth KN, Southerland AM, Summers DV, Tirschwell DL, American Heart Association Stroke Council. 2018 guidelines for the early management of patients with acute Ischemic stroke: a guideline for healthcare professionals from the American heart association/American stroke association. Stroke. 2018;49:e46-110.

8. Turk AS 3rd, Siddiqui A, Fifi JT, De Leacy RA, Fiorella DJ, Gu E, Levy EI, Snyder KV, Hanel RA, Aghaebrahim A, Woodward BK, Hixson HR, Chaudry MI, Spiotta AM, Rai AT, Frei D, Almandoz JED, Kelly M, Arthur A, Baxter B, English J, Linfante I, Fargen KM, Mocco J. Aspiration thrombectomy versus stent retriever thrombectomy as first-line approach for large vessel occlusion (COMPASS): a multicentre, randomised, open label, blinded outcome, non-inferiority trial. Lancet. 2019;393:998-1008.

9. Bendszus M, Fiehler J, Thomalla G. New interventional stroke trials. Clin Neuroradiol. 2019;29:1. 